\title{
Binostril versus mononostril approaches in endoscopic transsphenoidal pituitary surgery: clinical evaluation and cadaver study
}

\author{
*Jens Conrad, MD, ${ }^{1}$ Ali Ayyad, MD, ${ }^{1}$ Christian Wüster, MD, PhD, ${ }^{2}$ Wael Omran, MD, ${ }^{3}$ \\ Matthias M. Weber, MD, PhD, ${ }^{4}$ Moritz A. Konerding, MD, PhD, ${ }^{5}$ Wibke Müller-Forell, MD, PhD, ${ }^{6}$ \\ Alf Giese, MD, PhD, ${ }^{1}$ and Joachim Oertel, MD, PhD \\ ${ }^{1}$ Neurochirurgische Klinik und Poliklinik, ${ }^{4}$ Abteilung für Endokrinologie und Stoffwechselerkrankungen, and ${ }^{6}$ Institut für \\ Neuroradiologie, Universitätsmedizin, and ${ }^{5}$ nstitut für Anatomie und Zellbiologie, Fachbereich Medizin, Johannes Gutenberg- \\ Universität Mainz; ${ }^{2}$ Hormon- und Stoffwechselzentrum; ${ }^{3}$ Endokrinologische Praxis, Mainz; and ${ }^{7}$ Klinik für Neurochirurgie, \\ Universitätsklinikum des Saarlandes, Homburg/Saar, Germany
}

OBJECTIVE Over the past 2 decades, endoscopy has become an integral part of the surgical repertoire for skull base procedures. The present clinical evaluation and cadaver study compare binostril and mononostril endoscopic transnasal approaches and the surgical techniques involved.

METHODS Forty patients with pituitary adenomas were treated with either binostril or mononostril endoscopic surgery. Neurosurgical, endocrinological, ophthalmological, and neuroradiological examinations were performed. Ten cadaver specimens were prepared, and surgical aspects of the preparation and neuroradiological examination were documented.

RESULTS In the clinical evaluation, $0^{\circ}$ optics were optimal in the nasal and sphenoidal phase of surgery for both techniques. For detection of tumor remnants, $30^{\circ}$ optics were superior. The binostril approach was significantly more time consuming than the mononostril technique. The nasal retractor limited maneuverability of instruments during mononostril approaches in 5 of 20 patients. Endocrinological pituitary function, control of excessive hormone secretion, ophthalmological outcome, residual tumor, and rates of adverse events, such as CSF leaks and diabetes insipidus, were similar in both groups.

In the cadaver study, there was no significant difference in the time required for dissection via the binostril or mononostril technique. The panoramic view was superior in the binostril group; this was due to the possibility of wider opening of the sella in the craniocaudal and horizontal directions, but the need for removal of more of the nasal septum was disadvantageous.

CONCLUSIONS Because of maneuverability of instruments and a wider view in the sphenoid sinus, the binostril technique is superior for resection of large tumors with parasellar and suprasellar expansion and tumors requiring extended approaches. The mononostril technique is preferable for tumors with limited extension in the intra- and suprasellar area.

http://thejns.org/doi/abs/10.3171/2015.6.JNS142637

KEY WORDS binostril; mononostril; neuroendoscopy; pituitary surgery; transsphenoidal

$\mathrm{S}$ URGICAL approaches to the pituitary gland have undergone numerous refinements over the last 100 years. Successful application of the transseptal transsphenoidal approach to the pituitary gland was first described by Hermann Schloffer in 1906. This procedure became the most commonly used approach for resection of pituitary adenomas and is associated with a low rate of morbidity. ${ }^{29}$ In 1910, Hirsch described a direct endonasal approach to the sphenoid sinus and to the sella, but this technique included resection of the middle turbinate and parts of the nasal septum. ${ }^{19}$ Halstead published the sublabial gingival approach in the same year. ${ }^{17}$ In the 1960 s and after introduction of the operating microscope, Hardy combined lateral fluoroscopy with microsurgical techniques. This significantly improved magnification and illumination, reduced the risk of brain injury, und increased

ABBREVIATIONS ACTH = adrenocorticotrophic hormone; ENT = ear, nose, and throat; FSH = follicle-stimulating hormone; GH = growth hormone; IGF-1 = insulin-like growth factor-1; LH = luteinizing hormone; TSH = thyroid-stimulating hormone.

SUBMITTED November 16, 2014. ACCEPTED June 3, 2015.

INCLUDE WHEN CITING Published online January 1, 2016; DOI: 10.3171/2015.6.JNS142637.

* Drs. Conrad and Oertel contributed equally to this work. 
the rate of tumor resection as well as the percentage of favorable outcomes. ${ }^{18}$

The introduction of new technical skills, endoscopy, neuronavigation, and intraoperative imaging opens new avenues and widens the spectrum of accessible lesions. ${ }^{7}$

Inspired by use of endoscopic paranasal sinus surgery by otorhinolaryngologists, several groups almost simultaneously started to apply the endoscope in pituitary adenoma surgery since the mid-1990s. ${ }^{20,23}$ Endoscopic transnasal transsphenoidal procedures theoretically offer various advantages over the transsphenoidal microsurgical approach, such as a wider view of the surgical field, optimal illumination and high image definition, less damage to the nasal anatomy and mucosa, technical advantages in the treatment of recurrences, and reduced rates of overall complications..$^{6,22}$

Endoscopic intrasellar surgery not only offers the possibility of eradicating endosellar tumor, but also the possibility of eradicating parasellar tumor under direct visual control using rigid endoscopes with angled optics $\left(0^{\circ}, 30^{\circ}\right.$, $45^{\circ}$, and even $70^{\circ}$ ). This can very rarely be done in a standard microscopic transnasal transsphenoidal operation..$^{3,9,24}$

Endoscopic transsphenoidal surgery is defined as a procedure performed by visualization using the endoscope alone throughout the procedure. The binostril approach through both nostrils uses no nasal retractors or specula; in contrast, because of the limited space through 1 nostril, the mononostril approach is often performed with a nasal speculum as an integral part of the procedure. ${ }^{26}$ Even though both techniques are currently in wide use, there is little evidence as to which technique is superior. ${ }^{2,11,21,22} \mathrm{At}$ our institution, the binostril technique was established by Robert Reisch ${ }^{10}$ as a variant of the strategy introduced by Paolo Cappabianca, ${ }^{4}$ whereas the mononostril technique was introduced by the senior author (J.O.). ${ }^{28}$

The aim of this clinical evaluation was to determine the advantages of binostril versus mononostril endoscopic transnasal transsphenoidal approaches for simple and complex pituitary adenomas with respect to surgical feasibility, technical limitations, and patient outcome. A cadaver study examined and quantified the "endoscopic panoramic view" based on identification of anatomical landmarks at different levels of the approach and with various optics. These results were compared with respect to the size of the opening of the sphenoid floor and the extent of resection of the nasal septum.

\section{Methods}

From October 2008 to November 2009, 40 patients with newly diagnosed pituitary adenoma underwent endoscopic transnasal transsphenoidal tumor resections at the Department of Neurosurgery, University of Mainz, Germany. In this evaluation, 20 consecutive cases in which patients were treated by means of an endoscopic mononostril approach and 20 consecutive cases in which the patients were treated by means of a binostril approach were retrospectively analyzed based on video data (Fig. 1). Patients who had undergone previous pituitary surgery and patients with lesions other than pituitary adenomas were excluded from this evaluation.

Each of the study groups (mononostril and binostril) in-

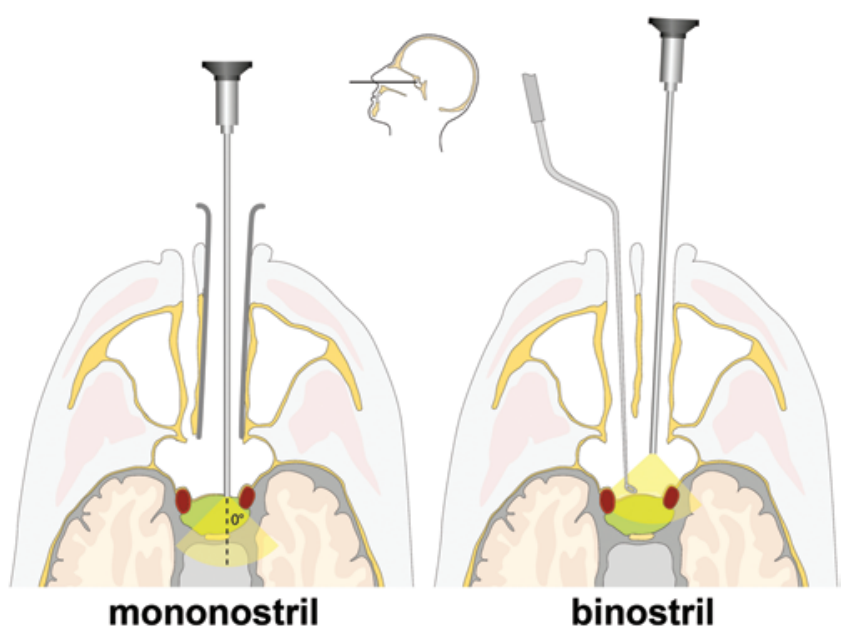

FIG. 1. Illustration of the mononostril and binostril approaches and schematic field of view by $0^{\circ}$ optics. Illustration by Stefan Kindel. Copyright Department of Neurosurgery, Universitätsmedizin Mainz. Published with permission. Figure is available in color online only.

cluded 10 female and 10 male patients. The patients' mean age at the date of surgery was 64 years (range 19-86 years) in the binostril group and 49 years (range $23-79$ years) in the monostril group. The mean duration of follow-up in both groups was 42 months (range 36-48 months).

The preoperative examination included a complete endocrinological workup in basal conditions (plasma growth hormone [GH], insulin-like growth factor-1 [IGF-1], prolactin, adrenocorticotrophic hormone [ACTH], cortisol, thyroid-stimulating hormone [TSH], free thyroxin, luteinizing hormone [LH], follicle-stimulating hormone [FSH], testosterone, and estradiol levels) and after hormonal stimulation of the pituitary gland with hypothalamic releasing hormones (Table 1). All tumors were submitted to immunohistochemical analysis. Patients were evaluated endocrinologically at the 6-, 12-, 24-, 36-, and 48-month follow-up visits. For patients who undergo surgery for a clinically secretory adenoma, the criteria for determination of remission vary depending on the tumor type. For patients with prolactinoma, the criterion is a normal serum prolactin level. For patients with acromegaly, the criteria are a normal value of IGF-1 and a suppression of GH excretion of less than $1.0 \mathrm{ng} / \mathrm{ml}$ during an oral glucose tolerance test. For patients with ACTH adenomas, remission is determined on the basis of the serum cortisol level, urinary free cortisol excretion, nighttime salivary cortisol testing, ACTH level, and the dexamethasone suppression test. Another criterion for patients with secretory adenomas is the clinical follow-up and the remission of symptoms.

All patients were followed up with MRI focused on the sellar region, including coronal and sagittal views-2, 3, or a maximum of $3.5-\mathrm{mm}$ slice thickness - with native and contrast-enhanced sequences. In 13 of 40 cases MRI was performed at the Institute of Neuroradiology at the University Hospital Mainz, and in the remaining 27 cases, the imaging studies were performed at various different institutions. Additional cranial CT studies (Toshiba Aquilion, 32 slices) including high-resolution reconstruction (bone window, slice thickness $0.5 \mathrm{~mm}$ ) in the sagittal, coronal, and axial planes was performed to evaluate the pre- and 
TABLE 1. Preoperative clinical parameters in the binostril and mononostril group

\begin{tabular}{lcc}
\hline \multicolumn{1}{c}{ Characteristic } & Binostril $(n=20)$ & Mononostril $(n=20)$ \\
\hline Nonfunctioning adenomas & 16 & 13 \\
\hline Functioning adenomas & 4 & 7 \\
\hline Prolactin & 1 & 1 \\
\hline GH & 2 & 5 \\
\hline GH/Prolactin & 1 & 0 \\
\hline ACTH & 0 & 1 \\
\hline Pituitary insufficiency & 10 & 9 \\
\hline ACTH & 5 & 3 \\
\hline LH/FSH & 1 & 2 \\
\hline TSH/ACTH & 1 & 0 \\
\hline TSH/LH/FSH & 1 & 0 \\
\hline LH/FSH/GH & 0 & 1 \\
\hline LH/FSH/GH/ACTH & 0 & 2 \\
\hline LH/FSH/GH/ACTH/TSH & 2 & 1 \\
\hline Visual field deficit & 8 & 6 \\
\hline Double vision & 3 & 0 \\
\hline
\end{tabular}

postoperative anatomy of the nasal, sphenoidal, and sellar skeleton and soft tissue. Tumor size was classified according to maximum tumor diameter in 2 categories: microadenoma $(<10 \mathrm{~mm})$ and macroadenoma $(\geq 10 \mathrm{~mm})$. The macroadenomas were further classified according to their extensions as intrasellar, suprasellar, and invasive to the cavernous sinus. The Knosp classification system was used to quantify invasion of the cavernous sinus, in which only Grades 3 and 4 define true invasion of the tumor into the cavernous sinus (Table 2). The average preoperative volume of the tumors in the binostril group was $5.65 \pm$ $5.26 \mathrm{~cm}^{3}$ (maximum lateral width $2.5 \mathrm{~cm}$ and maximum craniocaudal dimension $3.5 \mathrm{~cm}$ ), in the mononostril group $4.73 \pm 5.33 \mathrm{~cm}^{3}$ (maximum lateral width $2.5 \mathrm{~cm}$ and maximum craniocaudal dimension $3.7 \mathrm{~cm}$ ). Follow-up cranial CT scans performed obtained immediately after surgery, and MRI was performed 6, 12, 24, 36 and 48 months postoperatively. In patients with clinical or radiological evidence of chiasmal compression or invasion of cavernous sinus, an ophthalmological examination was performed (Table 1). Postoperative rhinological function was evaluated with respect to breathing either subjectively (on the basis of the patient's reported experience) or objectively (by means of otorhinolaryngological examination), and the sense of smell was objectively tested by means of a "Sniffin sticks" test battery (Screening 12 Test, Burghardt Messtechnik).

\section{Surgical Procedures in Patients}

Surgery was performed with orotracheal intubation and general anesthesia; the oropharyngeal region was packed with a gauze roll to minimize the risk of blood aspiration at the time of extubation. Cefazolin was given 30 minutes before surgery. The patients were positioned supine, with the upper part of the body slightly elevated to about $20^{\circ}$. The head was tilted to the right and placed on a horseshoe head rest. Lateral fluoroscopy (C-arm) was used
TABLE 2. Tumor size and growth pattern

\begin{tabular}{lcc}
\hline \multicolumn{1}{c}{ Size \& Growth Pattern } & Binostril & Mononostril \\
\hline Microadenomas & 1 & 3 \\
\hline Macroadenomas & & \\
\hline Intrasellar & 0 & 2 \\
\hline Intrasellar \& suprasellar & 12 & 12 \\
\hline Intrasellar \& involving CS & 3 & 2 \\
\hline Intrasellar, suprasellar, \& involving CS & 4 & 1 \\
\hline Total & 20 & 20 \\
\hline
\end{tabular}

CS = cavernous sinus.

for intraoperative imaging. The nose and the nasal cavities were treated with application of a nasal decongestant and an alcohol-based disinfectant. Four-millimeter rigid rodlens bayonet-shaped endoscopes with $0^{\circ}$ - and $30^{\circ}$-angled optics were used in the mononostril approach (Karl Storz $\mathrm{GmbH} \& \mathrm{Co} . \mathrm{KG})$. In the binostril approach, 4-mm rigid rod-lens endoscopes were also used, but they were straight and fitted with a suction/irrigation device (Richard Wolf $\mathrm{GmbH}$ ). The surgical equipment was equipped with a Xenon Nova 300 cold light source, a high-definition (HD) Image-1 H3 three-chip HD camera and an AIDA recording device (all Karl Storz GmbH \& Co. KG).

The patient, $\mathrm{C}$-arm, and all endoscopic equipment were draped with sterile drapes. The neurosurgeon was positioned on the right side of the patient. All procedures were performed by 3 neurosurgeons with individual experience of more than 50 endoscopic sellar procedures in both techniques (J.C., A.A., J.O.). The surgical procedure and maneuverability of instruments were rated in 3 categories: feasible, restricted, and impossible. A rating of "feasible" indicates that the workflow was unimpaired; "restricted" indicates that the procedure was possible but associated with limitations; and the rating of "impossible" indicates that it was necessary to switch to another technique or another approach.

\section{Binostril Approach}

No nasal retractor was used for this approach. Surgery began with endoscopic identification of the nasal septum, inferior and middle turbinates, and nasopharynx through the right nostril. After lateralization of the right middle turbinate with the speculum and dissector and identification of sphenoid ostium and sphenoethmoidal recess, the sphenoid ostium was enlarged with a low-speed drill and rongeur (Fig. 2a-c). Fluoroscopy was used to control the extent of the opening of the sphenoid sinus. The same procedure was performed through the contralateral nostril, and the binostril approach was completed (Fig. 2d). The dorsal parts of the nasal septum were removed. After enlargement of both sphenoid ostia and removal of the sphenoid septum, the following anatomical landmarks in the sphenoid sinus were identified: sella, clivus, carotid prominence, sphenoid plane, optic protuberance, and the opticocarotid recess. Instruments such as a suction cannula, a curette, or a knife could be introduced very comfortably through either nostril (Fig. 2e). Opening of the floor of the sella with a low-speed drill and enlargement with rongeurs constituted the next steps (Fig. 2f). After fixa- 

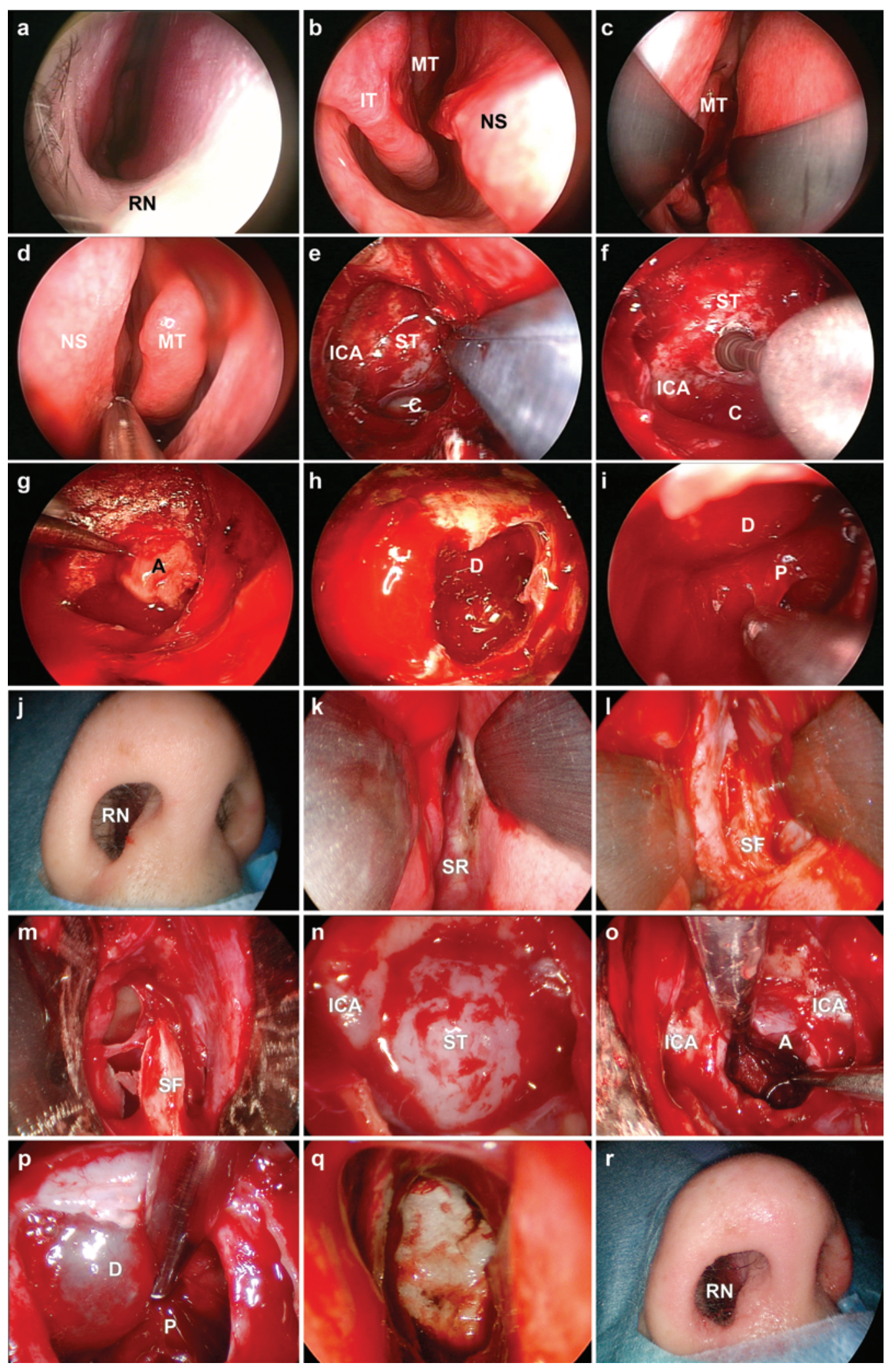

FIG. 2. Intraoperative endoscopic images. a-i: Binostril approach. $A=$ adenoma; $C=$ clivus; $D=$ diaphragm; $I C A=$ prominence of the internal carotid artery; $\mathrm{IT}=$ inferior turbinate; $\mathrm{MT}=$ middle turbinate; $\mathrm{NS}=$ nasal septum; $\mathrm{P}=$ pituitary tissue; $\mathrm{RN}$ = right nostril; ST = sella turcica. $\mathbf{j}-\mathrm{r}$ : Mononostril approach. $\mathrm{SF}=$ sphenoid floor; $\mathrm{SR}=$ sphenoethmoidal recess. Figure is available in color online only. 


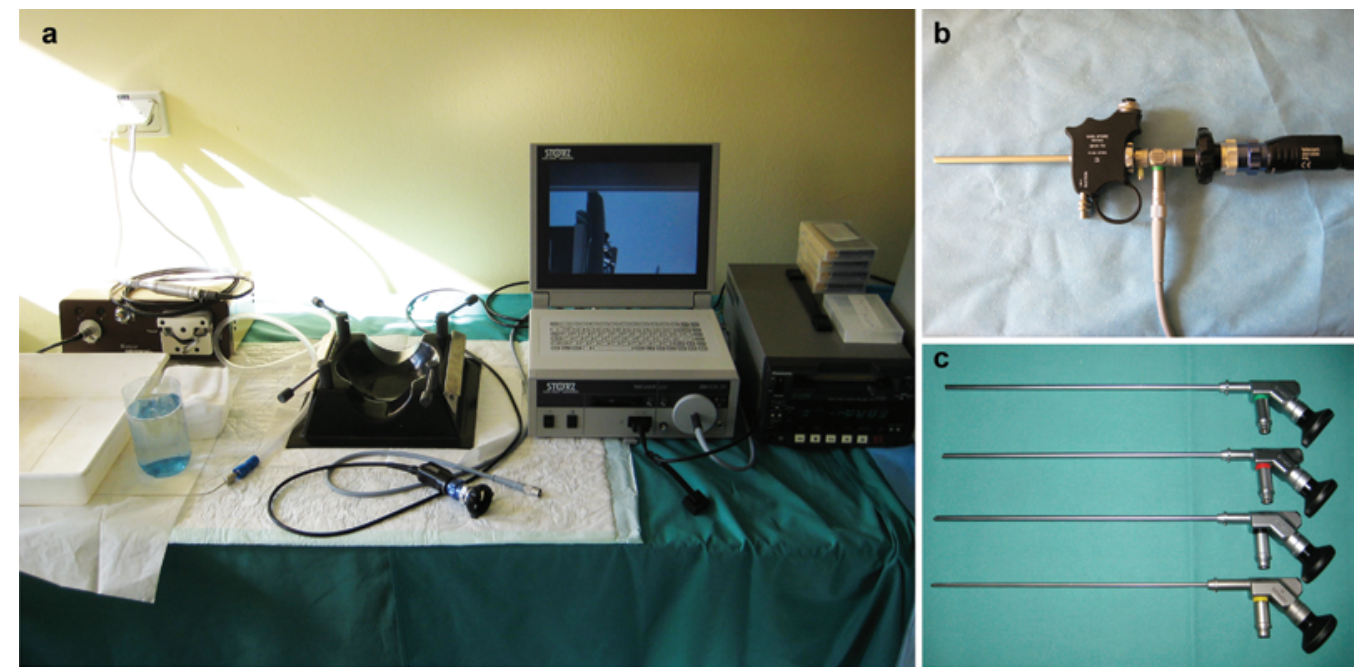

FIG. 3. Photographs of the experimental laboratory setup (a), a straight endoscope with suction/irrigation for binostril technique (b), and bayonet-shaped endoscopes for mononostril approaches $\left(0^{\circ}, 30^{\circ}, 45^{\circ}\right.$ and $70^{\circ}$, upper to lower) (c). Figure is available in color online only.

tion of the endoscope on a holding device and positioning through the left nostril, the neurosurgeon, using a 2-hand technique, opened the dural layer with scissors and the tumor was removed with slow movements using curettes and suction cannula (Fig. $2 \mathrm{~g}$ and h). The endoscope was then introduced inside the sella. For inspection of the sella for tumor remnants, we used the $30^{\circ}$-angled endoscope (Fig. 2i). Sellar reconstruction was performed using Gelfoam and Tabotamp fibrillar (Johnson \& Johnson Medical $\mathrm{GmbH}$ ). In case of an intraoperative CSF leak, sellar reconstruction was performed using a fat graft and fibrin glue. A lumbar drain was placed as required. At the end of the procedure, blood was removed from the orotracheal region; nasal packing was not used routinely.

\section{Mononostril Approach}

A mononostril approach was employed in 20 patients. The right nostril was routinely selected in 20 cases; in 1 case the left nostril was used because of a septum deviation to the right side. After coagulation of the septal mucosa in the sphenoethmoidal recess, the septal mucosa was incised, the septum was fractured to the left, and a nasal speculum was inserted (Fig. 2j-1). The sphenoid ostia were identified, and the sphenoid floor was resected (Fig. 2m). After identification of the sellar landmarks, such as floor of the sella, carotid prominence, and optic canal, the sella was opened and the tumor was resected with curettes (Fig. $2 \mathrm{n}$ and $\mathrm{o}$ ). At the end of the tumor resection, the sella was inspected with a $30^{\circ}$-angled endoscope for tumor remnants (Fig. 2p). The sphenoid floor was reconstructed with Gelfoam and in some cases with sphenoid bone (Fig. 2q). The main differences from the binostril approach were the manipulation through only 1 nostril (Fig. 2r) and the use of a self-retaining nasal retractor.

\section{Cadaver Study}

Ten fresh-frozen cadaveric heads originating from whole-body donations to the Institute of Functional and
Clinical Anatomy were studied. High-resolution cranial CT (Toshiba Aquilion) with reconstruction (bone window, slice thickness $0.5 \mathrm{~mm}$ ) in sagittal, coronal, and axial planes was performed before and after the dissection to evaluate the anatomy of the nasal, sphenoidal, and sellar skeleton. The CT showed a postsellar type of sphenoid sinus in 8 specimens and a presellar type of sphenoid sinus in 2 specimens; thus the 10 cadavers were divided into 2 groups of 5 , with each group including 4 specimens with the postsellar type and 1 specimen with the presellar type. Preparation was performed in the neurosurgical laboratory; heads were fixed in a head shell in an elevated position; and no lateral fluoroscopy was used. For the mononostril approach the same type of endoscope was used as in the clinical evaluation (4-mm rigid rod-lens Bayonet $0^{\circ}, 30^{\circ}$, $45^{\circ}, 70^{\circ}$ ); in the binostril group, a straight endoscope fitted with a suction/irrigation similar to the clinical situation was used (endoscopic system from Karl Storz GmbH \& Co. KG). The system was completed by a compact device with a cold light source, a standard definition camera and monitor (tele pack, Karl Storz GmbH \& Co. KG), and a microTRON 60 drill (Aesculap AG) (Fig. 3a-c).

The binostril approach was identical to the clinical evaluation but orientation was possible using only landmarks (inferior and middle turbinate, nasal septum, choana, sphenoethmoid recess, sphenoid ostium) and no fluoroscopy.

Both $0^{\circ}$ and $30^{\circ}$ optics were available. As in a mononostril procedure in the clinical situation, a nasal retractor was placed in the right nostril for the mononostril technique in the cadaver specimens. At the end of both procedures (i.e., after reaching the sella), the sella was opened and intrasellar structures were inspected.

To evaluate both techniques, anatomical landmarks were registered at different levels in the nasal and sphenoid phase and with various optics (Fig. $4 \mathrm{a}-\mathrm{c}$ ). The maneuverability of instruments were rated in 3 categories: feasible, restricted, and impossible.

Statistical significance was analyzed via 2-tailed MannWhitney U-test. 

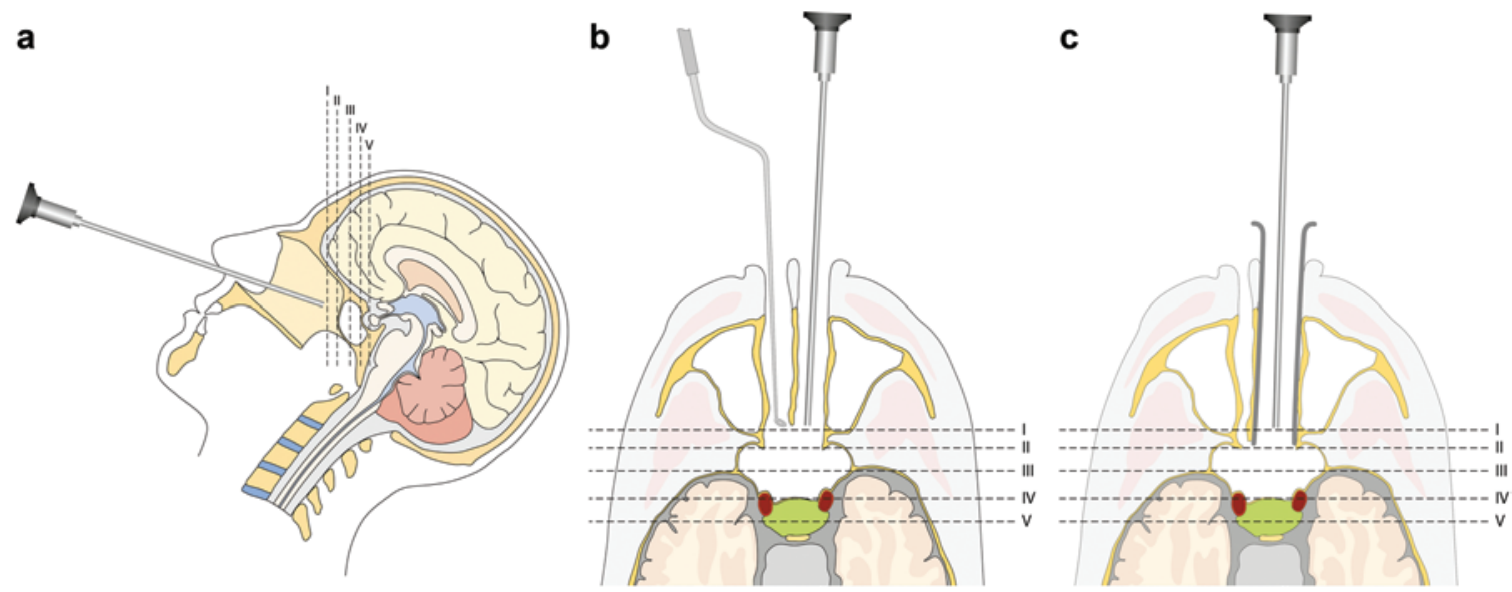

FIG. 4. Illustration of the approach levels (I-V) in the sagittal plane (a) and axial plane (b and c) during the binostril (b) and mononostril (c) approach. The levels are defined as follows: I, $1 \mathrm{~cm}$ before sphenoid sinus anterior wall; II, at the level of sphenoid sinus anterior wall; III, center of sphenoid sinus; IV, frontal wall of the sella; and V, inside the sella. Illustration by Stefan Kindel. Copyright Department of Neurosurgery, Universitätsmedizin Mainz. Published with permission. Figure is available in color online only.

\section{Results}

\section{Clinical Evaluation}

Nonfunctioning adenomas were the most common type of pituitary adenomas in the 2 groups -16 cases in the binostril and 13 in the mononostril group. Hormone-secreting adenomas were observed in 4 patients treated with the binostril approach and 7 treated with the mononostril approach. Preoperatively, pituitary insufficiency was found in 10 and 9 cases in the binostril and mononostril groups, respectively. In the binostril group, ophthalmological examination revealed visual field deficits in 8 patients and double vision caused by infiltration of the cavernous sinus in 3 patients; in the mononostril group, the corresponding numbers were 6 and 0 (Table 1).

The mean duration of operating time was significantly longer in binostril procedures than in mononostril procedures $(123 \pm 40$ [SD] vs $93 \pm 28$ minutes, $\mathrm{p}<0.01$, 2-tailed Mann-Whitney U-test). The number of patients with intraoperatively or postoperatively observed CSF leaks, secretory control of functioning adenomas, resolution of preoperative pituitary insufficiency, new postoperative insufficiency of pituitary gland, and resolution or improvement of visual field defects did not differ significantly in the 2 groups. Similarly, the difference in the number of patients with residual tumor or diabetes insipidus did not reach statistical significance (Table 3). Residual tumor was detected in 4 patients in the binostril group (in the cavernous sinus in 3 patients and in the supra- and retrosellar region in one) and 2 patients in the mononostril group (parasellar in the cavernous sinus in 1 patient and intrasellar in the other). The patient with intrasellar residual tumor had a $\mathrm{GH}$-secreting adenoma and had received preoperative hormonal drug treatment. Nasal packing was performed in 4 patients who were treated via a mononostril approach. The maneuverability of instruments and view of anatomical landmarks were rated "restricted" by the surgeon due to the nasal retractor in 5 of 20 procedures performed via a mononostril approach.

Rhinological examination revealed a persistent nasal obstruction by synechiae in 2 patients in the binostril group and by crusts in 1 patient in the mononostril group. This required ENT treatment. Four patients from each group complained of a temporary nasal obstruction (Table 4).

Permanent hyposmia occurred in 2 patients in the binostril group and 1 patient in the mononostril group; there was no permanent anosmia (Table 4).

In both approaches, $0^{\circ}$ optics were optimal for the nasal and sphenoid phases of surgery, whereas intrasellar control of residual tumor, particularly suprasellar und parasellar tumor, required $30^{\circ}$ optics, which provided optimal visualization of these regions.

Use of a nasal speculum in mononostril approaches narrowed the surgical corridor and limited visualization and restricted handling of instruments. In 5 of 20 procedures, this significantly restricted the workflow and tumor resection, particularly in patients with large tumors. In no

TABLE 3. Surgical results and clinical outcome in patients treated via binostril or mononostril approaches

\begin{tabular}{lcc}
\hline \multicolumn{1}{c}{ Result/Outcome } & $\begin{array}{c}\text { Binostril, } \\
\mathrm{n}=20\end{array}$ & $\begin{array}{c}\text { Mononostril, } \\
\mathrm{n}=20\end{array}$ \\
\hline Operating time in minutes (mean $\pm \mathrm{SD}$ ) & $123 \pm 40$ & $93 \pm 28^{*}$ \\
\hline CSF leak intraoperatively & 6 & 4 \\
\hline Restrictions by nasal speculum & - & 5 \\
\hline Nasal packing required & 0 & 4 \\
\hline Control of functioning adenomas & $2 / 4$ & $5 / 7$ \\
\hline Resolution of preop pituitary insufficiency & $1 / 10$ & $1 / 9$ \\
\hline New postop insufficiency & 3 & 1 \\
\hline \multicolumn{1}{c}{ ACTH deficiency } & 3 & 1 \\
\hline Resolution of visual field deficits & $7 / 8$ & $5 / 6$ \\
\hline Visual field deficits unchanged & $1 / 8$ & $1 / 6$ \\
\hline Resolution/improvement of double vision & $3 / 3$ & $0 / 0$ \\
\hline Residual tumor & 4 & 2 \\
\hline Diabetes insipidus, permanent & 1 & 0 \\
\hline
\end{tabular}

${ }^{*} p<0.01$. 
TABLE 4. Rhinological aspects in patients treated by binostril or mononostril approaches

\begin{tabular}{lcc}
\hline \multicolumn{1}{c}{ Feature } & $\begin{array}{c}\text { Binostril, } \\
\mathrm{n}=20\end{array}$ & $\begin{array}{c}\text { Mononostril, } \\
\mathrm{n}=20\end{array}$ \\
\hline No complaints regarding nose breathing & 14 & 15 \\
\hline Temporary nasal obstruction & 4 & 4 \\
\hline Persistent nasal obstruction \& ENT treatment & 2 & 1 \\
\hline Hyposmia \& anosmia & & \\
\hline No hyposmia & 13 & 13 \\
\hline Transient hyposmia & 5 & 6 \\
\hline Permanent hyposmia & 2 & 1 \\
\hline Anosmia & 0 & 0 \\
\hline
\end{tabular}

case did a mononostril or binostril procedure have to be converted from one to the other technique.

\section{Illustrative Cases}

Binostril Technique

This 35-year-old man complained of intermittent visual deficits. A MRI scan was performed, and a large macroadenoma with intra-, para-, and suprasellar extension and a size of $35 \times 25 \times 35 \mathrm{~mm}$ was detected (Fig. 5). Despite elevation of the optic chiasm on MRI, ophthalmological examination showed no visual field deficits. Endocrinological investigation showed no hormonal activity but a partial adenohypophyseal dysfunction. The sphenoid sinus was explored via a binostril approach. The endoscopic image using the $0^{\circ}$ and $30^{\circ}$ optic (Richard Wolf $\mathrm{GmbH}$ ) allowed ideal visual control of tumor resection with direct observation of the intracavernous carotid artery. Because of opening of the diaphragma sellae, sellar reconstruction was performed using fat tissue and fascia lata, and a lumbar drain was placed for 5 days. The postoperative CT scan showed a 22-mm horizontal opening in the sphenoid sinus (Fig. 5f). Postoperative MRI demonstrated complete resection of the tumor. The patient's endocrinological status was unchanged at 30 months after the operation; no adverse events were observed-in particular, no diabetes insipidus. No respiratory complaints or hyposmia occurred. The operating time in this case was 150 minutes because of the reconstruction of the sella using fat and fascia.

\section{Mononostril Technique}

This 37-year-old woman suffered from acromegaly, amenorrhea, and fatigue. The initial examination included evaluation of hormonal status, which revealed excessive levels of GH $(6.78 \mathrm{ng} / \mathrm{ml})$ and IGF-1 $(1069.0 \mathrm{ng} / \mathrm{ml})$ and a gonadotroph malfunction. An MRI scan showed a pituitary tumor of $17 \times 17 \mathrm{~mm}$ with intra- and suprasellar extension
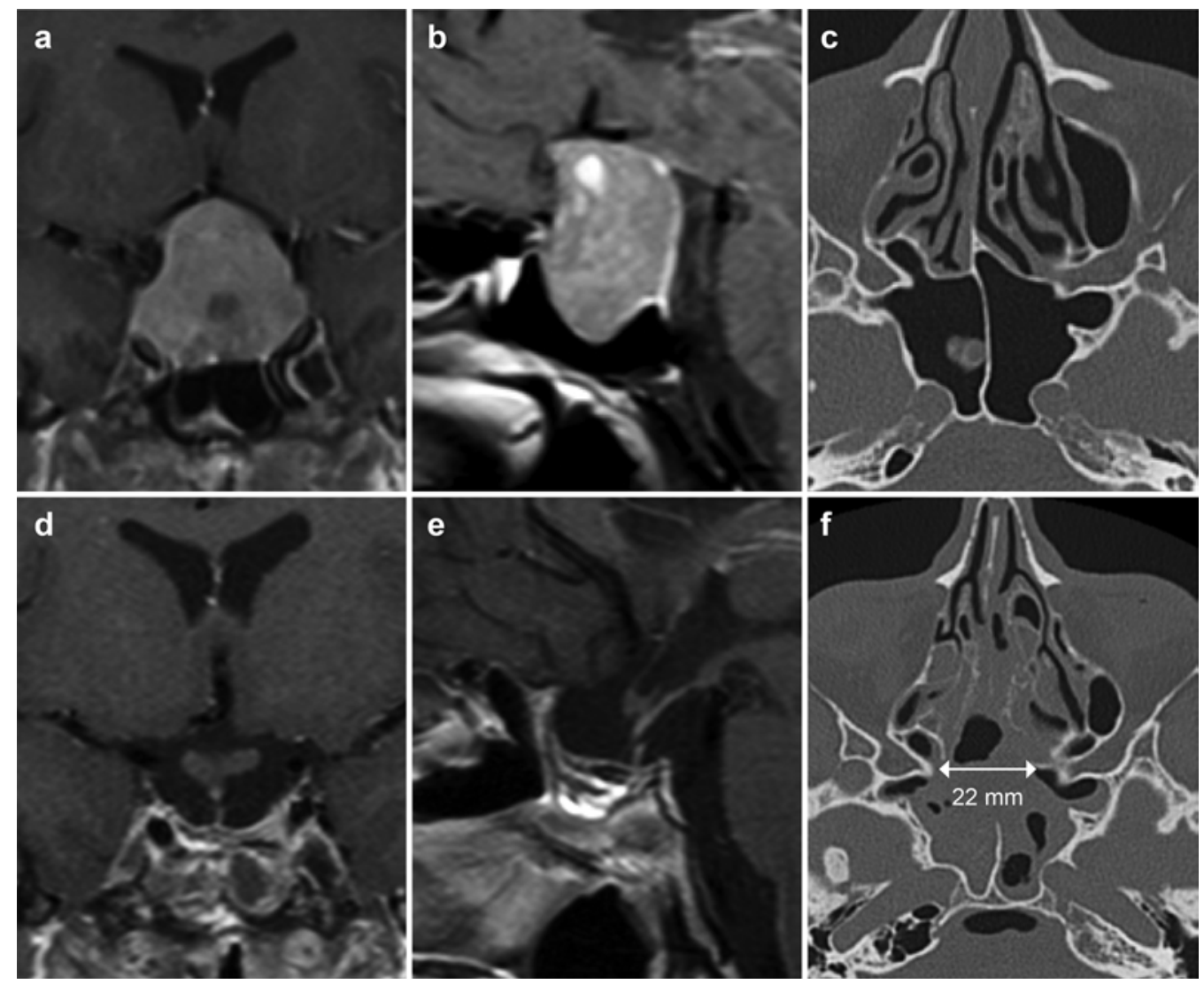

FIG. 5. Upper: Preoperative T1-weighted contrast-enhanced coronal (a) and sagittal (b) MR images and preoperative axial CT image (c). Lower: Postoperative T1-weighted contrast-enhanced coronal (d) and sagittal (e) MR images obtained at the 6-month follow-up evaluation and CT image obtained on postoperative Day 4 (f). MR images courtesy of "Gemeinschaftspraxis für Radiologie und Nuklearmedizin," Mainz, Germany. 

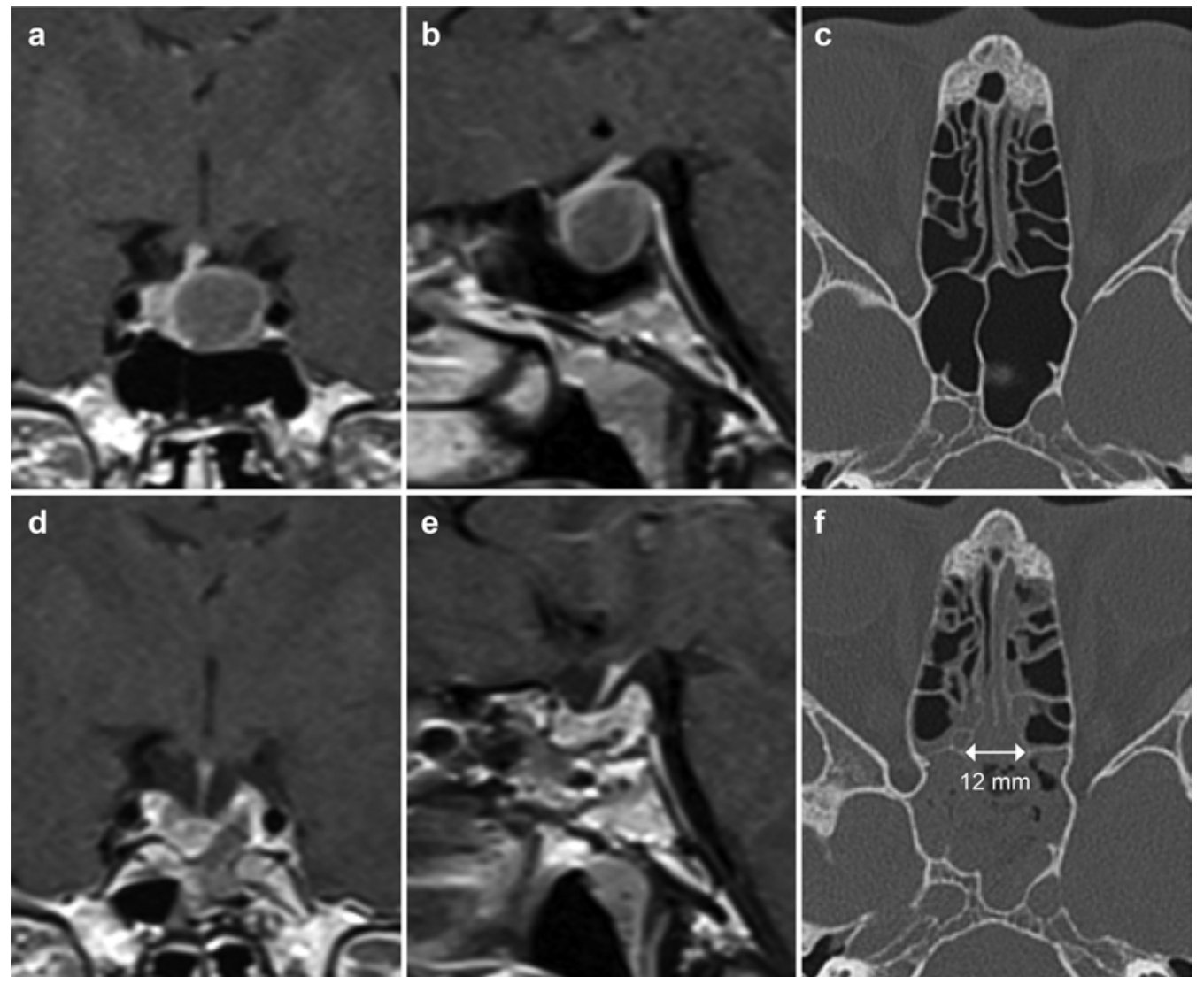

FIG. 6. Upper: Preoperative T1-weighted contrast-enhanced coronal (a) and sagittal (b) MR images and preoperative CT image (c). Lower: Postoperative CT image obtained on Day 2 (f) and T1-weighted contrast-enhanced coronal (d) and sagittal (e) MR images obtained 4 months after surgery. MR images courtesy of "Gemeinschaftspraxis für Radiologie und Nuklearmedizin," Mainz, Germany.

and no compression of the optic chiasm (Fig. 6). Surgery was performed via a mononostril approach through the right nostril using a nasal speculum. Tumor removal was done using $0^{\circ}$ and $30^{\circ}$ optics (Karl Storz GmbH \& Co. $\mathrm{KG}$,). No complications occurred intraoperatively-specifically, no CSF leak was observed. Endocrinological studies revealed biochemical control of the acromegaly and normal neuro- and adenohypophyseal function. Using the mononostril technique with a nasal speculum, a 12-mm horizontal opening of the sphenoid sinus was possible and complete removal of the tumor was achieved (Fig. 6f). The surgeon described a limitation of instrument handling resulting in poor control of the wall of the left cavernous sinus. The patient complained about transient obstruction of nasal respiration and hyposmia. The operating time was 93 minutes.

\section{Cadaver Study}

In each group, CT scans before dissection revealed 4 postsellar and 1 presellar type of sphenoid sinus. The time required for the approach up to Level $\mathrm{V}$ did not differ significantly between the 2 approaches, with a mean duration of 76.6 minutes (range 64-90 minutes) in the binostril group and 75 minutes (range 62-90 minutes) in the mononostril group. There were no signs of previous surgery in any of the specimens. Table 5 shows the results of identification of anatomical landmarks in 5 cadavers per group at Level I to III with $0^{\circ}$ and $30^{\circ}$ optics. At Level I $(1 \mathrm{~cm}$ before the anterior wall of the sphenoid sinus) and Level II (at the level of anterior wall of the sphenoid sinus), the binostril technique ( $0^{\circ}$ optics) is superior with respect to the ability to identify landmarks (light gray shading in Table 5). At Level III (center of the sphenoid sinus), after passing the anterior wall of the sinus, no advantage could be identified (dark gray shading in Table 5). Use of $30^{\circ}$ optics at Level I-III presents a panoramic view in the cranial direction and was particularly suitable for inspection of the protuberance of the optic nerve and the opticocarotid recess. In contrast to $45^{\circ}$ and $70^{\circ}$ optics, $30^{\circ}$ optics have the great advantage of a straight view, resulting in easy and reliable handling. The $70^{\circ}$ optics presented difficulties with respect to handling and orientation, and $45^{\circ}$ has no benefits in visualization compared with $30^{\circ}$; therefore, the results for $45^{\circ}$ and $70^{\circ}$ optics are not shown in Table 5. Having no pituitary lesion, the cadavers showed no widening of the sella; however, at Level IV (frontal wall of the sella) and Level V (inside the sella) $30^{\circ}$ optics were superior regardless of the approach (Figs. 7 and 8).

In both the mononostril group and the binostril group, the sphenoid sinus was opened as widely as possible during the preliminary phase of the approach. Binostril approaches without nasal retractors allow a wider opening in the craniocaudal and horizontal directions but require more manipulation of the nasal septum (Table 6, Fig. 9). 
TABLE 5. Identification of anatomical structures at Level I-III with $0^{\circ}$ and $30^{\circ}$ optics with binostril or mononostril technique in 10 cadavers (per group)*

\begin{tabular}{|c|c|c|c|c|c|c|c|c|}
\hline \multirow[b]{2}{*}{ Level \& Group } & \multicolumn{2}{|c|}{ ICA } & \multicolumn{2}{|c|}{ Optic Nerve } & \multicolumn{2}{|c|}{ OC Recess } & \multirow[b]{2}{*}{ Clivus } & \multirow[b]{2}{*}{ Sphenoid Plane } \\
\hline & Right & Left & Right & Left & Right & Left & & \\
\hline \multicolumn{9}{|l|}{ Level I, $0^{\circ}$} \\
\hline $\mathrm{Bi}$ & 5 & 4 & 3 & 2 & 3 & 2 & 5 & 5 \\
\hline Mono & 3 & 3 & 0 & 0 & 1 & 1 & 5 & 5 \\
\hline \multicolumn{9}{|l|}{ Level I, $30^{\circ}$} \\
\hline $\mathrm{Bi}$ & 4 & 3 & 5 & 4 & 5 & 4 & 3 & 5 \\
\hline Mono & 3 & 3 & 2 & 3 & 2 & 3 & 3 & 5 \\
\hline \multicolumn{9}{|l|}{ Level II, $0^{\circ}$} \\
\hline $\mathrm{Bi}$ & 5 & 5 & 5 & 4 & 5 & 3 & 5 & 5 \\
\hline Mono & 4 & 4 & 2 & 3 & 2 & 4 & 5 & 5 \\
\hline \multicolumn{9}{|l|}{ Level II, $30^{\circ}$} \\
\hline $\mathrm{Bi}$ & 2 & 2 & 5 & 4 & 5 & 4 & 1 & 5 \\
\hline Mono & 3 & 3 & 4 & 4 & 4 & 5 & 3 & 5 \\
\hline \multicolumn{9}{|l|}{ Level III, $0^{\circ}$} \\
\hline $\mathrm{Bi}$ & 5 & 5 & 5 & 4 & 5 & 4 & 5 & 5 \\
\hline Mono & 4 & 4 & 3 & 3 & 4 & 4 & 5 & 5 \\
\hline \multicolumn{9}{|l|}{ Level III, $30^{\circ}$} \\
\hline $\mathrm{Bi}$ & 2 & 2 & 5 & 5 & 5 & 5 & 1 & 5 \\
\hline Mono & 3 & 3 & 4 & 4 & 4 & 5 & 3 & 5 \\
\hline $\begin{array}{l}\mathrm{Bi}=\text { binostril; ICA = in } \\
\text { * Because } 5 \text { cadaver } \\
\text { tril) is } 5 . \text { As can be se } \\
\text { optics with respect to } \\
\text { was found at Level III } \\
\text { able for inspection of }\end{array}$ & $\begin{array}{l}\text { arotid } \\
\text { used fo } \\
\text { the re } \\
\text { ity to id } \\
\text { levels } \\
\text { uberan }\end{array}$ & $\begin{array}{l}\text {; Mono } \\
\text { h grout } \\
\text { in the c } \\
\text { landn } \\
\text { of } 30^{\circ}\end{array}$ & $\begin{array}{l}\text { nostril; } \\
\text { aximum } \\
\text { ded ligh } \\
\text { Level I } \\
\text { t Level I } \\
\text { e and th }\end{array}$ & $\begin{array}{l}\text { opticoc } \\
\text { e for ide } \\
\text { y, clearl } \\
\text { evel II. } \\
\text { rovides } \\
\text { icocaro }\end{array}$ & $\begin{array}{l}\text { ation of a } \\
\text { erior resu } \\
n \text { be seer } \\
\text { oramic } \mathrm{V}\end{array}$ & $\begin{array}{l}\text { ucture } \\
\text { ere obt } \\
\text { the } \mathrm{ce} \\
\text { the } \mathrm{cr}\end{array}$ & $\begin{array}{l}\text { single gro } \\
\text { d with the } \\
\text { haded dar } \\
\text { I direction }\end{array}$ & $\begin{array}{l}\text { binostril or mononos- } \\
\text { stril technique and } 0^{\circ} \\
\text { ay, no such advantag } \\
\text { was particularly suit- }\end{array}$ \\
\hline
\end{tabular}

Instrument maneuverability was unrestricted in 3 cadavers per group. In the mononostril group, the nasal retractor restricted the workflow during the preliminary phase of the approach in 2 specimens, and in the binostril group handling was restricted during the preliminary phase in 2 specimens because the front lens of the endoscope was repeatedly blurred by contact with the mucosa. This obscuration of the endoscope was the effect of doing the preliminary approach without a nasal retractor but not a function of the cadaver preparation.

No mononostril or binostril procedure had to be converted to the other technique.

\section{Discussion}

The transnasal transsphenoidal approach to sellar tumors has evolved into an elaborate technique since its first description in the early 20th century. Within the last 2 decades, strictly endoscopic surgical techniques have become an integral part of the surgical armamentarium for sellar procedures, and publications addressing their application are frequent. ${ }^{1,16}$ The ability of the endoscope to provide a wide panoramic and detailed view of anatomical structures is the main advantage of endoscopic techniques over microsurgical techniques. ${ }^{12,13,30}$ Another advantage of endoscopic techniques compared with microsurgery is the extended view of intra-, para-, and suprasellar structures that may be obtained using angled endoscope optics and angled instruments to visualize and manipulate residual tumor in these areas. ${ }^{4}$ In our hands, direct illumination and visualization by the endoscope are easier than and superior to the use of mirrors in microsurgery. For individual surgeons, switching from microsurgical to endoscopic procedures may be difficult and even discouraging mainly because of difficulties managing the initial intranasal phase of the approach. ${ }^{8,25}$ The current literature focuses on 2 major techniques for the endoscopic transnasal approach to the sella, with or without use of a speculum. With help of a nasal speculum, which is used to dilate the working channel, the neurosurgeon reaches the sphenoid sinus through 1 nostril, the mononostril or monoportal approach. The advantage of endoscopic mononostril approaches compared with microsurgical techniques, both using a speculum, is the possibility of introducing the endoscope into the sphenoid sinus and beyond inside the sellar cavity, which, for example, allows distinguishing tumor tissue from pituitary gland because of superior illumination and image definition. Tunnel effects of the speculum limiting illumination and the lateral view in microsurgical approaches are less relevant in endoscopic approaches; however, the speculum still restricts the bimanual handling of instruments..$^{14}$ The second surgical technique, using a binostril or biportal approach, typically does not require a nasal speculum. ${ }^{5,15,27} \mathrm{~A}$ direct comparison of mononostril or binostril approaches and their specific advantages has not previously been presented in the literature. 

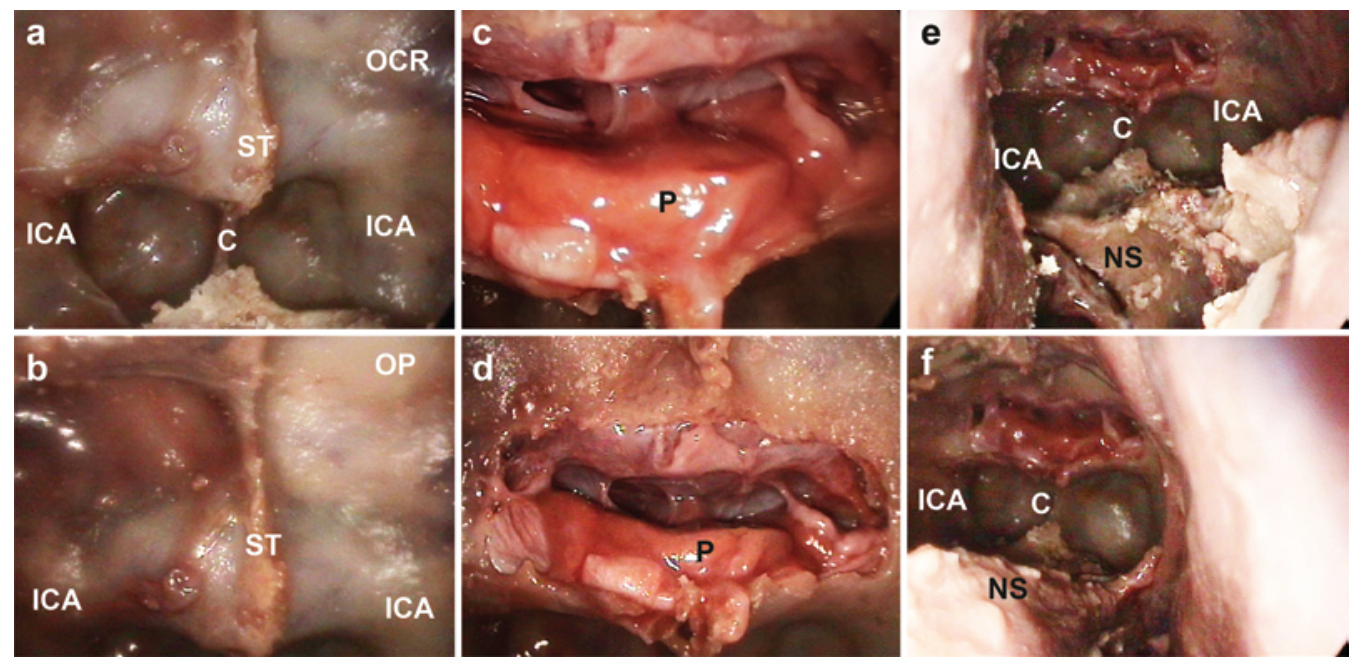

FIG. 7. Images obtained in a cadaver from the binostril approach group: Level II viewed through a $0^{\circ}$ endoscope (a); Level II, $30^{\circ}$ (b); Level IV, $0^{\circ}$ (c); Level IV $30^{\circ}$ (d); overview from the right (e) and left side (f) with $0^{\circ}$ showing the larger resection of nasal septum in comparison to the mononostril technique. $C=$ clivus; ICA = prominence of the internal carotid artery; NS = nasal septum; $\mathrm{OCR}=$ opticocarotid; $\mathrm{OP}=$ optic nerve prominence; $\mathrm{P}=$ pituitary tissue; $\mathrm{ST}$ = sella turcica. Figure is available in color online only.

In our evaluation, a team of pituitary surgeons with individual experience of greater than 50 endoscopic sellar procedures analyzed 40 cases of pituitary tumors treated by means of binostril or mononostril approaches. Analysis was done retrospectively based on video recordings and surgical records. The main difference between the 2 techniques was the operating time, which was shorter in the mononostril technique, but at the cost of restricted handling of instruments because of a narrow working channel through a speculum that has to accommodate the endoscope and surgical instruments. Other parameters such as residual tumor, CSF fistulas, rhinological aspects, and results of endocrinological or ophthalmological examinations were not significantly different. Limitations on maneuverability of instruments by a speculum are often mentioned in the literature as a disadvantage but the maneuverability was never directly compared by the same neurosurgeons performing both techniques. In this series, in 5 of 20 cases in which a mononostril approach was used, handling of the suction cannula, curettes, and endoscope was limited by the narrow channel created by the nasal speculum. In theory, the speculum protects the nasal anatomy from being injured by instruments moving in and out of the sella. Our data, however, demonstrate that intranasal hemorrhage due to injury of the nasal mucosa was more frequent in mononostril approaches and was attributed to the speculum itself. In patients treated through binostril approaches we experienced no limitations of instrument handling because of the flexibility of nasal structures. Nostrils, turbinates, and the nasal septum can be gently displaced by the shaft of rigid instruments, but with the possibility of injury to the mucosa or nasal skeleton. As a consequence, the binostril technique needed more extensive coagulation of the mucosa but provided a wider working channel and allowed wider opening of the sphenoid sinus in craniocaudal and bilateral directions.
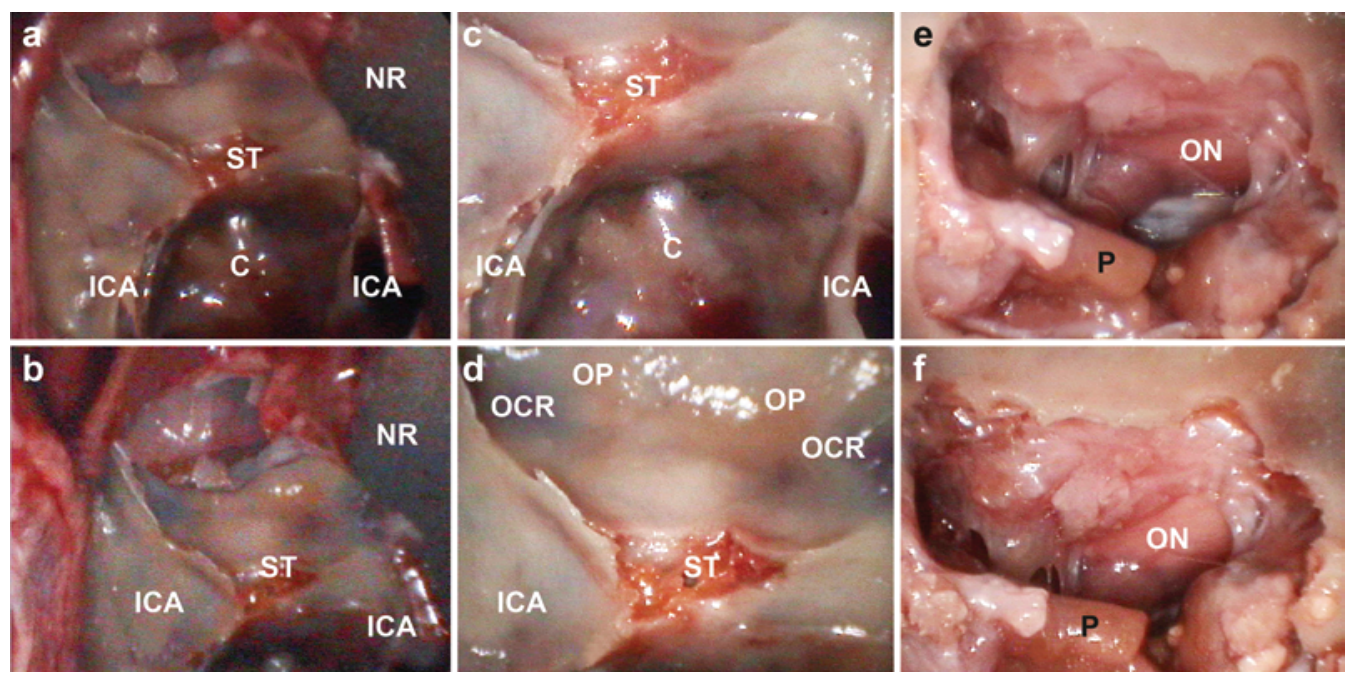

FIG. 8. Images obtained in a cadaver after mononostril dissection: Level I, $0^{\circ}$ (a); Level I $30^{\circ}$ (b); Level III, $0^{\circ}$ (c); Level III, $30^{\circ}$ (d); Level IV, $0^{\circ}(\mathrm{e})$; Level IV, $30^{\circ}$ (f). NR = nasal retractor; ON = optic nerve. Figure is available in color online only. 
TABLE 6. Opening of sphenoid sinus and resection of dorsal part of nasal septum in 10 cadavers*

\begin{tabular}{lcc}
\hline \multicolumn{1}{c}{ Description } & Binostril, $\mathrm{n}=5$ & Mononostril, $\mathrm{n}=5$ \\
\hline Craniocaudal opening & $17.4(14.3-22.5)$ & $14.9(12.4-17.2)$ \\
\hline Horizontal opening & $18.1(13.8-21,4)$ & $11.1(9.5-12.3)$ \\
\hline $\begin{array}{l}\text { Resection of dorsal part of } \\
\text { nasal septum }\end{array}$ & $9.5(7.3-11.6)$ & $2.7(0.0-7.6)$ \\
\hline
\end{tabular}

* Data represent the mean measurement in $\mathrm{mm}$ (range). The between-groups differences were not statistically significant for any of the measurements.

This resulted in a wider surgical field, allowing optimal control of vascular structures within the sphenoid sinus and an excellent panoramic view. In our series of 40 cases, no surgery was converted from mononostril to binostril technique. Moreover, no operation has been converted to microsurgery, either in the current series of 40 cases or in our whole series of approximately 450 endoscopic transsphenoidal procedures performed since 2004.

The cadaver study was performed by 1 neurosurgeon experienced in both techniques (J.C.). The results in terms of opening of the sphenoid sinus in the craniocaudal and horizontal directions matched the results of our clinical evaluation. In the cadaver study as in the clinical evaluation, the resection of the dorsal parts of the nasal septum was more extensive in the binostril approach. The wider surgical field noted in the binostril technique in the clinical evaluation was confirmed in the cadaver study based on the possibility of recognition of anatomical landmarks in the sphenoid sinus. In the cadaver study, the $0^{\circ}$ optic was excellent for the nasal and sphenoidal part of the approach, whereas the $30^{\circ}$ optic was superior in the sellar phase. Surprisingly, dissection time for the approach did not differ significantly between the 2 groups. The reason is that in a cadaver the binostril approach is much easier and faster than in clinical practice because of the larger nasal passage with a lack of mucosal swelling. In addition, because there is no hemorrhage in a cadaver, no coagulation is necessary, and the workflow is therefore much faster. As in the clinical evaluation, the nasal retractors restricted the handling in the mononostril approach ( 2 of 5 specimens); in the binostril technique; however, the front lens of the endoscope was repeatedly blurred by contact with the mucosa without the protection of a retractor ( 2 of 5 specimens).

In summary, both techniques are effective and safe. Because of the restrictions in mononostril approaches, it may be difficult to remove large tumors with this technique. Based on these findings, for very large adenomas extending to parasellar areas or significant infiltration of the cavernous sinus we favor use of a binostril technique without a speculum (Table 2).

\section{Conclusions}

Using endoscopic techniques in transsphenoidal pituitary surgery is safe and effective, and the endoscope, with its panoramic view and the option of angled optics, provides excellent intraoperative image information and anatomical overview. Binostril endoscopic approaches should be preferred for the treatment of larger tumors with significant parasellar and suprasellar extension and even in extended approaches because of better maneuverability of instruments, and, in cases of smaller tumors, mononostril approaches in combination with nasal speculum are significantly faster and also effective.
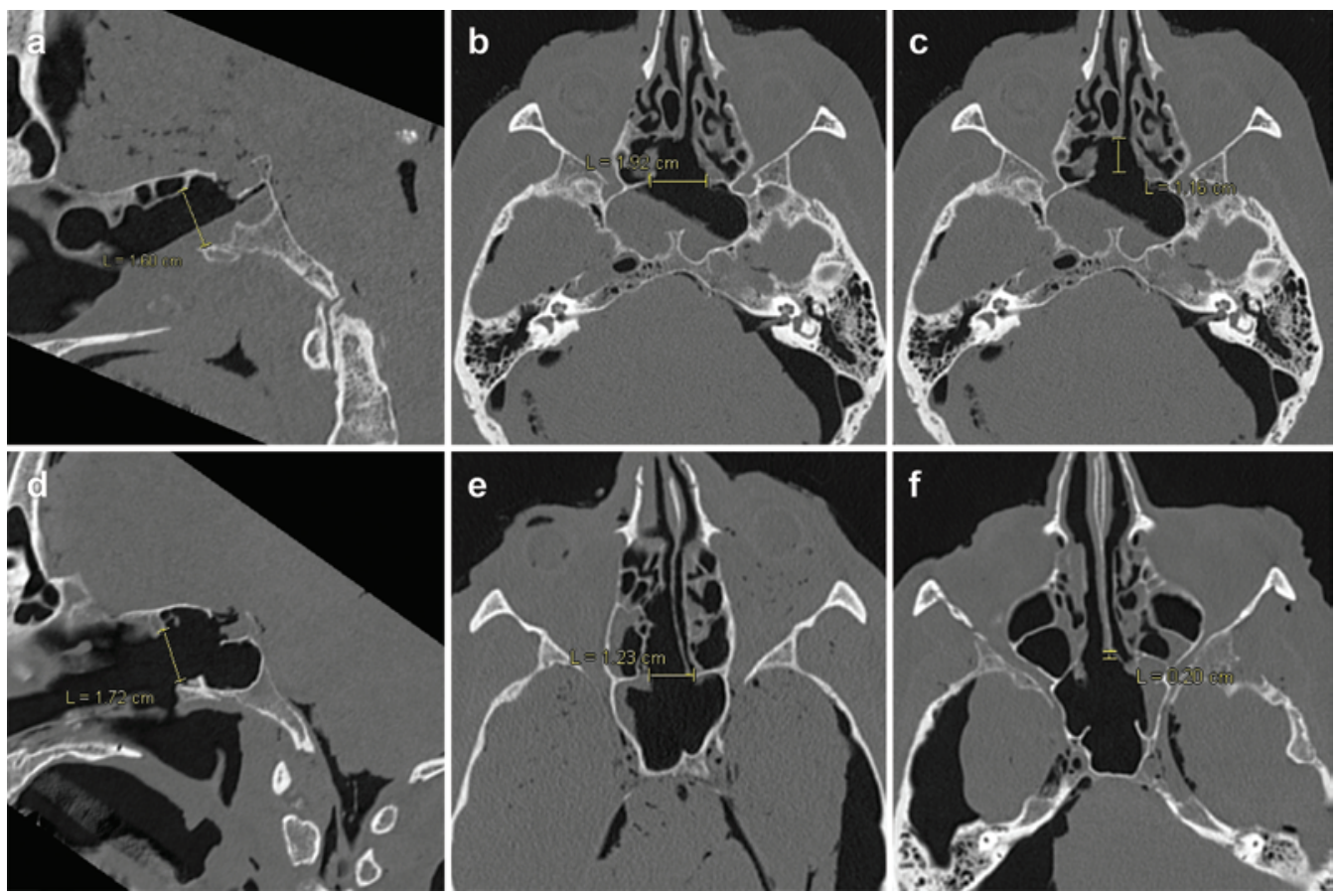

FIG. 9. Cranial CT images obtained in cadavers shown in Figs. 7 (a-c, binostril) and 8 (d-f, mononostril) in sagittal (a and d) and axial (b, $c, e$, and f) planes after preparation for demonstration of craniocaudal opening (a and d), horizontal opening (b and $e$ ), and resection of dorsal part of nasal septum (c and f). Figure is available in color online only. 


\section{Acknowledgments}

We express our sincere appreciation to Stefan Kindel for graphics and preparation of illustrations.

\section{References}

1. Buchfelder M: Treatment of pituitary tumors: surgery. Endocrine 28:67-75, 2005

2. Cappabianca P, Alfieri A, de Divitiis E: Endoscopic endonasal transsphenoidal approach to the sella: towards functional endoscopic pituitary surgery (FEPS). Minim Invasive Neurosurg 41:66-73, 1998

3. Cappabianca P, Cavallo LM, Colao A, Del Basso De Caro M, Esposito F, Cirillo S, et al: Endoscopic endonasal transsphenoidal approach: outcome analysis of 100 consecutive procedures. Minim Invasive Neurosurg 45:193-200, 2002

4. Cappabianca P, Cavallo LM, de Divitiis E: Endoscopic endonasal transsphenoidal surgery. Neurosurgery 55:933-941, 2004

5. Cappabianca P, Cavallo LM, de Divitiis O, Solari D, Esposito F, Colao A: Endoscopic pituitary surgery. Pituitary 11:385390,2008

6. Cappabianca P, Cavallo LM, Esposito F, de Divitiis E: Endoscopic endonasal transsphenoidal surgery: procedure, endoscopic equipment and instrumentation. Childs Nerv Syst 20:796-801, 2004

7. Cappabianca P, Decq P, Schroeder HW: Future of endoscopy in neurosurgery. Surg Neurol 67:496-498, 2007

8. Cavallo LM, Dal Fabbro M, Jalalod'din H, Messina A, Esposito I, Esposito F, et al: Endoscopic endonasal transsphenoidal surgery. Before scrubbing in: tips and tricks. Surg Neurol 67:342-347, 2007

9. Cavallo LM, Prevedello D, Esposito F, Laws ER Jr, Dusick JR, Messina A, et al: The role of the endoscope in the transsphenoidal management of cystic lesions of the sellar region. Neurosurg Rev 31:55-64, 2008

10. Charalampaki P, Reisch R, Ayad A, Conrad J, Welschehold S, Perneczky A, et al: Endoscopic endonasal pituitary surgery: surgical and outcome analysis of 50 cases. J Clin Neurosci 14:410-415, 2007

11. Chole RA, Lim C, Dunham B, Chicoine MR, Dacey RG Jr: A novel transnasal transsphenoidal speculum: a design for both microscopic and endoscopic transsphenoidal pituitary surgery. J Neurosurg 114:1380-1385, 2011

12. Conrad J, Philipps M, Oertel J: High-definition imaging in endoscopic transsphenoidal pituitary surgery. Am J Rhinol Allergy 25:e13-e17, 2011

13. de Divitiis E: Endoscopic transsphenoidal surgery: stone-inthe-pond effect. Neurosurgery 59:512-520, 2006

14. Fatemi N, Dusick JR, de Paiva Neto MA, Kelly DF: The endonasal microscopic approach for pituitary adenomas and other parasellar tumors: a 10-year experience. Neurosurgery 63 (4 Suppl 2):244-256, 2008

15. Frank G, Pasquini E, Farneti G, Mazzatenta D, Sciarretta V, Grasso V, et al: The endoscopic versus the traditional approach in pituitary surgery. Neuroendocrinology 83:240248, 2006

16. Gondim JA, Almeida JP, Albuquerque LA, Schops M, Gomes E, Ferraz T, et al: Endoscopic endonasal approach for pituitary adenoma: surgical complications in 301 patients. Pituitary 14:174-183, 2011

17. Halstead AE: Remarks on the operative treatment of tumors of the hypophysis. With the report of two cases operated on by an oro-nasal method. Surg Gynecol Obstet 10:494-502, 1910

18. Hardy J: Transphenoidal microsurgery of the normal and pathological pituitary. Clin Neurosurg 16:185-217, 1969
19. Hirsch O: Endonasal method of removal of hypophyseal tumors. With a report of two successful cases. JAMA 55:772774, 1910

20. Jankowski R, Auque J, Simon C, Marchal JC, Hepner H, Wayoff M: Endoscopic pituitary tumor surgery. Laryngoscope 102:198-202, 1992

21. Jho HD, Alfieri A: Endoscopic endonasal pituitary surgery: evolution of surgical technique and equipment in 150 operations. Minim Invasive Neurosurg 44:1-12, 2001

22. Jho HD, Alfieri A: Endoscopic transsphenoidal pituitary surgery: various surgical techniques and recommended steps for procedural transition. Br J Neurosurg 14:432-440, 2000

23. Jho HD, Carrau RL: Endoscopy assisted transsphenoidal surgery for pituitary adenoma. Technical note. Acta Neurochir (Wien) 138:1416-1425, 1996

24. Kalinin PL, Fomichev DV, Kadashev BA, Trunin IuK, Kapitanov DN, Alekseev SN, et al: [Methods of the endoscopic endonasal transsphenoidal adenomectomy.] Vopr Neirokhir 4:42-45, 2007 (Russian)

25. Leach P, Abou-Zeid AH, Kearney T, Davis J, Trainer PJ, Gnanalingham KK: Endoscopic transsphenoidal pituitary surgery: evidence of an operative learning curve. Neurosurgery 67:1205-1212, 2010

26. Linsler S, Gaab MR, Oertel J: Endoscopic endonasal transsphenoidal approach to sellar lesions: a detailed account of our mononostril technique. J Neurol Surg B Skull Base 74:146-154, 2013

27. Nakao N, Nakai K, Itakura T: A minimally invasive endoscopic transsphenoidal approach with an endonasal septal pushover technique by using a modified nasal speculum. Minim Invasive Neurosurg 49:20-24, 2006

28. Oertel J, Gaab M: Endoscopic endonasal transsphenoidal approach to sellar lesions: a detailed account of our technique. Presented at the 58. Jahrestagung der Deutschen Gesellschaft für Neurochirurgie, Leipzig, 2007 (Abstract) (http://www.egms.de/static/en/meetings/ dgnc2007/07dgnc034.shtml) [Accessed September 18, 2015]

29. Schloffer H: Zur Frage der Operationen an der Hypophyse. Beitr Klin Chir 50:767-817, 1906

30. Schroeder HW, Gaab MR: Intracranial endoscopy. Neurosurg Focus 6(4):e1, 1999

\section{Disclosures}

Karl Storz provided the authors with endoscopic equipment for clinical and cadaver application. Joachim Oertel acts as a consultant to the Karl Storz Company. The authors received no financial funding for this study.

\section{Author Contributions}

Conception and design: Conrad, Oertel. Acquisition of data: Conrad, Ayyad, Wüster, Omran, Weber, Müller-Forell, Oertel. Analysis and interpretation of data: Conrad, Ayyad, Wüster, Omran, Weber, Müller-Forell, Oertel. Drafting the article: Conrad. Critically revising the article: Wüster, Weber, Konerding, MüllerForell, Giese, Oertel. Reviewed submitted version of manuscript: Conrad. Approved the final version of the manuscript on behalf of all authors: Conrad. Administrative/technical/material support: Konerding, Oertel. Study supervision: Oertel.

\section{Correspondence}

Jens Conrad, Neurochirurgische Klinik und Poliklinik, Universitätsmedizin Mainz, Johannes Gutenberg-Universität, Langenbeckstr. 1, Mainz 55131, Germany. email: jens_conrad@web.de. 